\title{
Role of Ultrasonography in Predicting Gastro-oesophageal Varices in Patients with Liver Cirrhosis
}

\author{
Merina Gyawali,' Ramesh Raj Acharya ${ }^{2}$ \\ 'Department of Radiodiagnosis and Imaging, Manipal Teaching Hospital, Pokhara, Nepal, ${ }^{2}$ Department of Medicine, Manipal \\ Teaching Hospital, Pokhara, Nepal
}

\begin{abstract}
\section{Introduction}

Upper Gastrointestinal endoscopy is considered the best screening tool in detecting gastroesophageal varices in patients with cirrhosis. Ultrasonography of the abdomen can be used for assessment of liver and portal system. This research was undertaken to demonstrate that the portal vein diameter and splenic size by ultrasonography can be used as a non-invasive predictor of gastro-esophageal varices..
\end{abstract}

\section{Methods}

A cross-sectional hospital based study comprising of 290 consecutive patients with liver cirrhosis were enrolled between December 2019 to December 2020. Clinical profile at admission and sonological splenic size and portal vein diameter were studied in all cirrhotic patients. Patients were classified into 2 groups: one with presence of varices and second without varices. Data entry was done in Statistical Packages for the Social Sciences version 20.

\section{Results}

The mean age of subjects was $52 \pm 13.26$ years with a range of $27-82$ years of age $(\mathrm{M}: \mathrm{F}=2: 1)$. The commonest etiology of cirrhosis was chronic alcohol consumption. The prevalence of varices in cirrhotics was $42.8 \%$. Average portal vein diameter of patients without gastro-esophageal varices was $11.12 \pm 1.36 \mathrm{~mm}$, while it was $12.81 \pm 1.62 \mathrm{~mm}$ in patients with varices $(\mathrm{p}<0.001)$. Average spleen size in cirrhotics without varices was $12.44 \pm 1.32 \mathrm{~cm}$ and with varices was $14.32 \pm 2.42 \mathrm{~cm}$. This difference was also statistically significant $(\mathrm{p}<0.001)$.

\section{Conclusions}

Measurement of portal vein diameter and spleen size by ultrasonography can be recommended as a non invasive predictor for gastro-oesophageal varices in patients with liver cirrhosis .

Keywords: cirrhosis; portal vein diameter; spleen size; ultrasonography; gastro-oesophageal varices

Correspondence: Dr. Merina Gyawali, Department of Radio diagnosis and Imaging, Manipal College of Medical Sciences and Teaching Hospital, Pokhara, Nepal. Email: merinagyawali@gmail.com. phone: +977-9807265511. 


\section{INTRODUCTION}

Cirrhosis is defined as the histological development of regenerative nodules and fibrous bands in patients with chronic liver diseases, that can lead to end stage liver disease. ${ }^{1}$ In patients with liver cirrhosis, portal hypertension causes splenomegaly, dilatation of portal vein, and formation of portal systemic collaterals like gastro-esophageal varices. ${ }^{2}$ Rupture of these dilated gastro- esophageal varices is responsible for most common complication in the form of upper gastrointestinal bleed. ${ }^{3}$ These are associated with re-bleeding and increased mortality. The presence of gastro-esophageal varices has been considered a prognostic indicator. ${ }^{4}$

Upper Gastrointestinal endoscopy is considered the best screening tool in detecting gastroesophageal varices in patients with cirrhosis. ${ }^{5}$ Despite the advantages of endoscopy, it is an invasive method and has poor compliance. In a low income country like Nepal, every hospital is not well equipped with endoscopy or trained staffs. Ultrasound is a non invasive tool with high patients compliance and available in all hospitals within the country. Ultrasonography of the abdomen can be used for assessment of liver, spleen size, ascites and portal system. ${ }^{6}$. This research was undertaken to demonstrate that the portal vein diameter and splenic size by Ultrasonography can be used as a non-invasive predictor of gastro-esophageal varices in patients with cirrhosis of liver.

\section{METHODS}

The observational, cross-sectional, hospital based study was carried out in Department of Radiodiagnosis and Imaging at Manipal College of Medical Sciences Teaching Hospital, Pokhara, Nepal from December 2019 to December 2020. The study was approved and verified by the Institutional Review committee (MEMG/
IRC/385/GA). All consecutive patients aged above 18 years who presented to department of Radiodiagnosis and Imaging at Manipal Teaching Hospital at Pokhara, for ultrasonography with the diagnosis of cirrhosis of Liver were included in this study. Cirrhotic patients with endoscopic evidence of gastro esophageal varices were included in the case study group and those without varices were considered as control group. The minimum sample size calculated was 384 .

The following cases with portal hypertension were excluded from the study:

1. Other cases with portal hypertension, i.e., non cirrhotic portal fibrosis, Budd-Chiari syndrome, extra hepatic portal venous obstruction.

2. Critically ill patients, cirrhotic patients with hepatocellular carcinoma and those who fail to give consent.

A detailed history, general physical examination and clinical examination of the abdomen were carried out. A complete study of liver, spleen and portal system was done by Doppler ultrasonography (GE Healthcare GE Logiq P3, Chicago, Illinois, United States) using B-mode imaging with 3-5 MHz curved array transducer. Portal vein diameter and spleen size were measured by placing the patient in supine position during full inspiration. Measurement of more than $13 \mathrm{~cm}$ indicates enlargement of spleen. ${ }^{7}$ The portal vein diameter exceeding 13 $\mathrm{mm}$ in quiet respiration can be suggestive of portal hypertension. ${ }^{7}$

Each patient underwent endoscopicinvestigation by standard flexible gastro duodenal endoscope (PENTAX EPK 700, PENTAX JAPAN Inc). Endoscopy was done by consulatant gastroenterologist and presence of gastroesophageal varices and other findings were documented. Varices were classified as small $(\leq$ 
$5 \mathrm{~mm}$ diameter) or large ( $>5 \mathrm{~mm}$ diameter) when assessed with full insufflations. ${ }^{5}$ Computed Tomography scan (PHILIPS Ingenuity 128 CT Scanner, NETHERLANDS Inc) of abdomen was also done in few selected cases.

Data were collected on a structured Performa covering the relevant parameters for the study. Data were entered and evaluated with Statistical Packages for the Social Sciences (SPSS) version 20. All categorical data were expressed in absolute number and percentage. All numerical continuous data were expressed in mean \pm SD. The data analysis was done using Statistical Packages for the Social Sciences (SPSS) version 20. Chi squared test was used to test for significant difference of proportions (categorical data). All tests were analyzed with a 95\% confidence interval and a $\mathrm{P}$ value of $<0.05$ was considered significant.

RESULTS varices in upper GI endoscopy. The prevalence of varices in cirrhotics was thus $42.8 \%$. Rest, 166 were in the control group (non varices).

The mean age of subjects was $52 \pm 13.26$ years with a range of $27-82$ years of age. Patients were further classified as per sex and age groups as in table 1 with maximum cases in 41-59 years of age group. Chronic alcohol consumption accounted 98 (80 \%) of total cases. Sixteen cases $(13.3 \%)$ of cases were chronic hepatitis B. 4 cases (3.3\%) were diagnosed with chronic hepatitis B and rest $6(3.3 \%)$ were classified as cryptogenic.

These cirrhotic patents presented with varied clinical presentation as in table 2. The most common complaint was anorexia (95.2\%) followed by abdominal distension (83.4\%), vomiting (80\%) and jaundice (72.8\%).

Average portal vein diameter (PVD) of patients without gastro-esophageal varices measured by ultrasonography was $11.12 \pm 1.36 \mathrm{~mm}$, while it

\begin{tabular}{|c|c|c|c|c|c|}
\hline \multicolumn{2}{|l|}{ Parameters } & \multicolumn{3}{|l|}{ Age group } & \multirow[t]{2}{*}{ Total } \\
\hline & & $<40$ yrs & 41-59yrs & $\geq 60$ yrs & \\
\hline \multirow[t]{2}{*}{ With Varices } & Male & 12 & 38 & 26 & 76 \\
\hline & Female & 4 & 26 & 18 & 48 \\
\hline \multirow[t]{2}{*}{ Without Varices } & Male & 16 & 62 & 40 & 118 \\
\hline & Female & 5 & 25 & 18 & 48 \\
\hline Total & & 37 & 151 & 102 & 290 \\
\hline
\end{tabular}

A total of 302 cirrhotics patients presented to department of Radiodiagnosos and Imaging over the study period.Twelve were excluded due to lack of adequate data. Finally, 290 patients were enrolled for the study. The study population comprised of 194 (66.9\%) males and 96 (33.1\%) females (M:F=2:1). Among them, 124 patients had evidence of Gastro-esophageal was $12.81 \pm 1.62 \mathrm{~mm}$ in patients with varices This difference was statistically significant $(p<0.01)$. Patients with small varices had average PVD of $12.45 \pm 1.35 \mathrm{~mm}$ and those with large varices had $13.85 \pm 1.75 \mathrm{~mm}$. Average spleen size measured by ultrasonography in patients without varices was $12.44 \pm 1.32 \mathrm{~cm}$ and with varices was 14.32 $\pm 2.42 \mathrm{~cm}$. This difference was statistically 


\begin{tabular}{|lcc|}
\hline Table 2. Symptomatology of study subjects. $(\mathrm{n}=290)$ & \\
\hline Symptoms & Frequency & Percentage \\
\hline Anorexia & 276 & $95.2 \%$ \\
Abdominal distension & 242 & $83.4 \%$ \\
Vomiting & 232 & $80 \%$ \\
Jaundice & 211 & $72.8 \%$ \\
Limb swelling & 192 & $66.2 \%$ \\
UGl Bleed & 103 & $35.5 \%$ \\
Dyspnoea & 95 & $32.8 \%$ \\
Altered sensorium & 45 & $15.5 \%$ \\
\hline
\end{tabular}

significant $(p<0.01)$. Patients with small varices had average $13.8 \pm 1.25 \mathrm{~cm}$ and those with large varices had $15.4 \pm 1.28 \mathrm{~cm}$. al. ${ }^{12}$ and, Thomopoulos et al. ${ }^{13}$ found PVD of 13 $\mathrm{mm}$ and $13.5 \mathrm{~mm}$ respectively to be predictive for variceal detection in cirrhotic patients. There

Table 3. Sonological Measurements in variceal and non variceal groups.

\begin{tabular}{|llll|}
\hline Parameters & Variceal group $(\mathrm{n}=62)$ & Non variceal group $(\mathrm{n}=20)$ & $\mathrm{P}$ value \\
\hline Average portal vein diameter $(\mathrm{mm})$ & $12.81 \pm 1.62$ & $11.12 \pm 1.36$ & $\mathrm{p}<0.05$ \\
Average spleen size $(\mathrm{cm})$ & $14.32 \pm 2.42 \mathrm{~cm}$ & $12.44 \pm 1.32$ & $\mathrm{p}<0.05$ \\
\hline
\end{tabular}

\section{DISCUSSION}

In the current study, average portal vein diameter (PVD) of patients without gastroesophageal varices was $11.12 \pm 1.36 \mathrm{~mm}$, while it was $12.81 \pm 1.62 \mathrm{~mm}$ in patients with varices. In the Indian study by Mandal et al. ${ }^{8}$, average PVD of patients without gastro-esophageal varices was $11.545 \pm 1.514$ mmand with varices was $13.998 \pm 1.123 \mathrm{~mm}(\mathrm{p}<0.05)$. The average PVD was $11.78 \pm 1.58 \mathrm{~mm}$ in non-variceal group and $14.05 \pm 2.26 \mathrm{~mm}$ in variceal group $(\mathrm{p}<0.01)$ by Shanker et al. ${ }^{9}$ According to Bhattarai et al. ${ }^{10}$, in a previous study in Nepal, average portal vein diameter (PVD) of patients without gastrooesophageal varices was $10.82 \pm 1.18 \mathrm{~mm}$, while it was $13.69 \pm 1.10 \mathrm{~mm}$ in patients with varices $(p<0.01)$. The findings of all these studies are in consistency with our study. $\mathrm{Ng}$ et al. ${ }^{11}$ detected oesophaeal varices in cirrhosis patients even at a lower mean PVD of $11.5 \pm 2.4 \mathrm{~mm}$. Schepis et was $92.7 \%$ sensitivity and $90 \%$ specificity for prediction for presence of esophageal varices when the cutoff value of portal vein diameter was $>12.25 \mathrm{~mm}$ by Bhattarai et al. ${ }^{10}$ Shanker et al. ${ }^{9}$, reported PVD $>12.2 \mathrm{~mm}$ as a predictor of esophageal varices with sensitivity of $80 \%$, and specificity of $80 \%$.

Average spleen size of patients without varices was $12.44 \pm 1.32 \mathrm{~cm}$ and those with varices was $14.32 \pm 2.42 \mathrm{~cm}$ in the present study. Shanker et al. ${ }^{9}$ reported similar average spleen size in variceal group $(14.69 \pm 1.08 \mathrm{~cm})$ than those in non variceal group $(12.45 \pm 0.65 \mathrm{~cm})$. In a previous Nepalese study by Bhattarai et al. ${ }^{10}$, average spleen size of patients without varices was $12.66 \pm 2.15 \mathrm{~cm}$. and those with varices was higher $(15.50 \pm 1.01$ $\mathrm{cm})$. Thomopoulos et al. ${ }^{13}$ had reported spleen size more than $13.5 \mathrm{~cm}$ to be associated with gastro-esophageal varices, Even lower splenic size of $>13.15 \mathrm{~cm}$ and $>13.13 \mathrm{~cm}$ were associated 
with presence of gastro- esophageal varices in their studies by Serag et al. ${ }^{14}$ and Mandal et al. ${ }^{8}$ respectively. There was $94.5 \%$ sensitivity and $75 \%$ specificity for prediction for presence of esophageal varices when the cutoff value of spleen size for was $>13.9 \mathrm{~cm}$ by Bhattarai et al. ${ }^{10}$ Even at a lower cutoff value of spleen size $>13.5$ $\mathrm{cm}$, Shanker et al. ${ }^{9}$ reported $90 \%$ sensitivity and $80 \%$ specificity.

In the current study, it was found that when portal vein diameter and spleen size increased, gastro-oesophageal varices also transformed to higher grades. Our findings are in consistent with published literatures by Mandal et al. ${ }^{8}$, Shankar et al. ${ }^{9}$ and Nemichandra et al. ${ }^{15}$, Basnet et al. ${ }^{16}$ and Sharma et al. ${ }^{17}$ who have described positive correlation between portal vein diameter and grades of esophageal varices and also between spleen size and variceal grading.

\section{CONCLUSIONS}

In cirrhotic patients with portal hypertension, as portal vein diameter increases by $>12.8$ $\mathrm{mm}$ and as size of spleen increases by $>14.3$, $\mathrm{cm}$ there is increased risk of development of gastro-oesophageal varices. Grades of varices increase with increment of portal vein size and splenic size. Measurement of portal vein diameter and spleen size by ultrasonography can be utilised as a non invasive predictors for gastro-oesophageal varices in patients with liver cirrhosis. Ultrasonogarphy can be used not only for evaluating liver echotexture and ascites in patients with liver cirrhosis but can also be utilized in surveillance and long-term clinical monitoring for varices.

\section{REFERENCES}

1. De Franchis R, Primignani M. Natural history of portal hypertension in patients with cirrhosis. Clinics in liver disease. 2001;5(3):645-63.

2. Bosch J, Garcia-Pagan JC. Complications of cirrhosis. I Portal hypertension. J Hepatol 2000; 32 (1 Suppl): 141-56.

3. Bacon BR. Cirrhosis and its complications. In:, Kasper DL, Fauci AS, Hauser SL, Longo DL, Jameson JL, Loscalzo J, editors. Harrison's principles of internal medicine.19th ed. New York: Mc Graw Hill; 2012:2058-66.

4. D'Amico G, Garcia-Tsao G, Pagliaro L. Natural history and prognostic indicators of survival in cirrhosis: a systematic review of 118 studies. J Hepatol. 2006;44:217-31

5. Jensen DM. Endoscopic screening for

varices in cirrhosis : findings, implications and outcomes. Gastroenterology 2002 ; 122:1620-30

6. Li FH, Hao J, Xia JG, Li HL, Fang H, Haemodynamic analysis of oesophageal varices in patients with liver cirrhosis using colour Doppler ultrasound. World J Gastroenterol. 2005; 11 (29): 4560-5.

7. Koslin DB, Mulligan SA, Berland LL. Duplex assessment of the splanchnic vasculature. Semin Ultrasound CTMR 1992; 13:34-9.

8. Mandal L, Mandal SK, Bandyopdhyay D. Correlation of portal vein diameter and splenic size with gastro-esophageal varices in cirrhosis of liver. JIACM. 2011; 12(4):266-70.

9. Shanker R, Banerjee S, Ganguly S, Bansal S, Uppal A, Bhadauriya AS, et al. A Study of Association of Portal Vein Diameter 
and Splenic Size with Gastro-Esophageal Varices in Liver Cirrhosis Patients. IOSR Journal of Dental and Medical Sciences.2016; 15(9):125-9.

10. Bhattarai S, Dewan KR, Shrestha G, Patowary BS. Non-Invasive Predictors of Gastro-Oesophageal Varices. JNMA . 2017;56(207):298-303.

11. Ng FH, Wong SY, Loo CK, Lam KM, Lai CW, Cheng CS. Prediction of oesophagogastric varices in patients with liver cirrhosis. J Gastroenterol Hepatol. 1999;14(8):785-90.

12. Schepis $F$, Cammà $C$, Niceforo D, Magnano A, Pallio S, Cinquegrani M, et al. Which patients with cirrhosis should undergo endoscopic screening for esophageal varices detection? Hepatology. 2001;33(2):333-8

13. Thomopoulos KC, LabropoulouKaratza C, Mimidis KP, Katsakoulis EC, Iconomou G, Nikolopoulou VN. Noninvasive predictors of the presence of large oesophageal varices in patients with cirrhosis. Dig Liver Dis. 2003; 35(7):473-8.

14. Serag E, Dalia O. Study of noninvasive predictors of portal hypertension in liver cirrhotic Egyptian patients. Journal of American Science 2011; 7(1):962-968.

15. Nemichandra, Singh SK, Yadav KV, Shiakh N, Singh D, Singh K. Non Endoscopic Predictors of Esophageal Varices in Patients with Cirrhosis of Liver. IOSR Journal of Dental and Medical Sciences 2015:14(1):65-68.

16. Basnet A, Thapa J, Sapkota K, KCA. Portal Vein Diameter by Ultrasonography as a non-Invasive Predictor of Esophageal Varices, International Journal of Medicine \& Biomedical Sciences. 2017; 2(1):6-10

17. Sharma SK, Aggarwal R. Prediction of large oesophageal varices in patients with cirrhosis of the liver using clinical, laboratory and imaging parameters. Journal of Gastroenterology and Hepatology 22 (11): 1909-15.

Citation: Gyawali M, Acharya R. Role of Ultrasonography in Predicting Gastro-oesophageal Varices in Patients with Liver Cirrhosis. JCMS Nepal. 2021 ; 17(1);10-5. 